\title{
Assembling the Collective Experience of a Serious Game Mediation as an Interactional Practice
}

\author{
Alain Bovet and Marc Relieu \\ Institut Mines-Télécom, Télécom ParisTech, CNRS LTCI, Département SES, \\ Antenne Deixis-Sophia, Sophia Antipolis, France \\ \{alain.bovet, marc.relieu\} atelecom-paristech.fr
}

\begin{abstract}
Public installation settings provide a great opportunity to study how various participants orient to one or several screens. In this paper, we explore how visitors use the central tactile menu of a serious game installation with the assistance of a mediator. To study this interactional organization, we conducted a video-based analysis of co-participants' practices. We focus on the close analysis of two distinct configurations of talk and bodily activities, which connect participants to the artefact through various embodied practices.
\end{abstract}

Keywords: ethnomethodology, embodied interaction, video-based studies, serious game, public interfaces.

\section{Public Exhibits and Mediation}

Digital interactive technologies based on distinctive interfaces are spreading across a variety of public settings. While many interfaces aim to facilitate a so-called "natural" interaction with a single user, our interest lies in installations, such as art exhibits, serious games or other performances that have been designed for a public [1]. Digital serious games have provided new resources with which to transform conventional pedagogical approaches to sustainable development and energy consumption issues, on the one hand, and, on the other hand, to public participation into urban planning.

In this area, we have a specific interest in "the work of 'professional' members of a public performance setting: actors -who guide participants' conduct with the interface" [2]. This paper is concerned with the mutual constitution of the sense of the artefact, the interactional conduct of the activity and the configuration of participation through the mediation of such actors.

\section{Context}

\subsection{What Is Ecotype?}

Ecotype is a multi-screen installation in a dome, which has been opened to the public for ten days in Valbonne (Southern France). Ecotype has been developed as an experimental 
project, partly funded by a French regional administration. Based on collaboration between several teams, Ecotype was headed by two artistic associations (Le Hublot and Scene\&Act ${ }^{1}$ ). Ecotype is an innovative project which resists any attempt to describe it with a single description. It is a digital installation designed to achieve several goals in the domains of sustainable development and energy consumption, a pedagogical device aiming at understanding the interdependence between local and global planning decisions, a leverage for citizen participation in the planning decision process, a game in which participants obtain a score, an art installation with a music performance, etc. In this paper, we have chosen to put this diversity into brackets in order to focus on the actual and observable framing of the installation. In line with our interest in the co-participants' practical orientations, we examine the facticity of Ecotype as a local achievement [3].

\subsection{Visiting Ecotype}

The visitors of Ecotype had registered in advance for a one-hour visit, either alone or in groups ranging from 2 to 20 people. Every visit was animated by one of the two designers of Ecotype. Inside the dome, the visitors were showed a 3-minute presentation of the game. At the end of the presentation, the animator provided a number of explanations on the game and then some practical assistance.

It is on the modality of this assistance that we want to focus in this paper. We will analyse in two cases how the game itself was engaged by the visitors and the animator. An important part of this interaction was accomplished through gestures and gazes, by which the participants displayed orientations to several aspects of the installation.

\subsection{The Screen as an Activity Centre}

This screen is given a central position in several ways. It is the only publicly available action centre in the dome. It is set up at the centre of the dome on a floor stand. At the beginning of each visit, the animator is standing close to the screen. He invites the newcomers to gather at the same place and to adopt a postural orientation which facilitates their later gathering around the monitor. Therefore this spatial, oriented-to centrality prepares the participants to see it as a centre for action, as a public display of "where the action is" [4]. The animator demonstrates the touch-sensitive capabilities of the screen by initiating a first "blank" round in the game. Through talk, gestures and gaze, the animator highlights various components of the "interface": the colored map of the commune of Valbonne at the center of the screen; the right menu which proposes the selection of several actions.

\footnotetext{
${ }^{1}$ The two leaders, Frédéric Alemany and Benoît Colardelle, have a long-standing commitment to creating interactive exhibits. We thank Frédéric and Benoît for having launched this project and the Pacalabs Programme from the PACA Region for their financial support to Ecotype.
} 


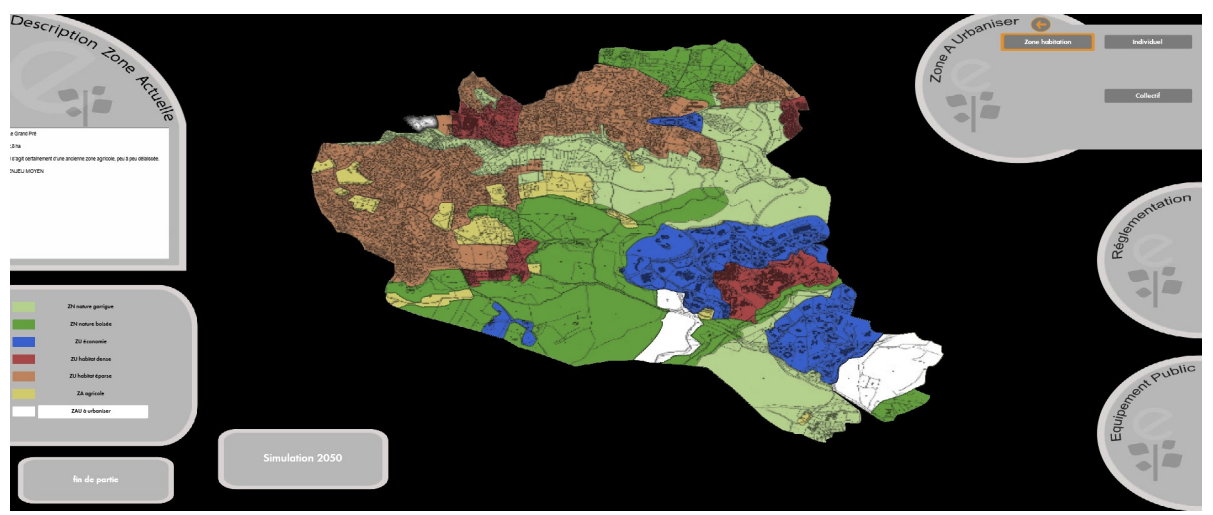

Fig. 1. Ecotype : the interface

The participants are invited to make a series of urban planning choices through this interface. But the map itself offers many opportunities for talk and action: participants are able to point towards specific areas, touch and select a particular area, or do other kinds of "spatial work" on it. Though the interface requires the assistance of an animator, it also encourages the participation of the visitor, acting as a "local planner".

\section{$3 \quad$ Method and Study}

A vivid and relatively new body of research has been concerned with the mutual adjustment of gesture, talk and other embodied practices through which co-participants constitute the local sense of artefacts in museums [2], [5-6]. Co-participants adjust their bodily and vocal activities to display various levels of participation and orientation towards specific features of the exhibits, which provide resources for the organization of those very activities. The focus on the social organization of participants' activities has brought a new emphasis on the embeddedness of any interaction into a material world [7-8]. This perspective has been developed through detailed analysis of video recordings. In line with theses studies, we installed three video cameras and two separate sound recorders inside the dome. This data collection process was complemented by a more traditional observational work. Our data consist in the recording and observation of more than 30 one-hour visits.

\section{$4 \quad$ Results}

In most cases, the task of handling the tactile interface was carried out by a single player, assisted by the animator. However, it produced a diversity of interactional arrangements. To quote Goodwin [7], "any participation framework is an ongoing contingent accomplishment, something not under control of a single party (who can at best make proposals about the structure of participation that should be operative at that moment), but rather something that has to be continuously achieved through public displays of orientation within ongoing processes of interaction." 


\subsection{Accomplishing the Mediation while Talking}

In the following fragment ${ }^{2}$, Tom, the animator, stands in front of the main screen with Paul, an incoming visitor. Both of them are co-oriented to the screen, side by side. This embodied formation facilitates both the orientation to the screen and the delivering of instructions. Tom frames the activity as a quasi-official political consultation. Then, Paul's participation is pre-figured, both vocally and non-verbally, as the expression of a verbal opinion. For Paul, acting as a local citizen and expressing an opinion addressed to the local administration about the planning decisions process becomes a relevant style of participation in this performance:

1 Tom

(.) et alors là on le plus important

2

and then here we- we- the most important

2 C'est des aussi les zones blanches. (.) qui are also the white zones which

3 sont les zones à urbaniser. are the zones to urbanise.

4 (1) alors une commune elle décide de so a municipality decides to

$5 \quad(0.5)$ eu: : :h de prendre les uh take the

6 espaces naturels, et eu:h de les ouvrir à natural spaces and to open them to l'urbanisation, (.) et là la commune voudrait urbanization. and here the municipality would savoir euh si vous qu'est-ce que vous soulike to know if you what would you haiteriez voir se développer euh comme types like to see develop uh as activity types d'activité sur la commune. in the municipality

12 Tom $(0.8)$

13 l'agriculture ou si vous voulez agriculture or if you want

14 conserver (.) ces to maintain(.)

15 ces [espaces natu]rels these natural spaces

16 Paul [les espaces verts]

green spaces

\footnotetext{
${ }^{2}$ We adopt the transcription conventions of conversation analysis [9].
} 
In the beginning of the turn, Tom highlights a series of specific areas on the visible map. This is done through the naming of the colour that singularizes these zones and through a syntactic construction by which he draws the attention of the hearer. Then, he adds a second unit (1.4) that offers a retrospective explanation for this highlighting: the white zones are also suitable to be urbanized, i.e. they are at stake for a planning decision process. This explanation is built to offer a more general remark about the kind of action which can be done by any municipality on this type of territory. More significantly, the white zones are redescribed, in this second unit of the same turn, as "natural spaces" to be urbanized (1.6). Then a third unit (1.7-10) is introduced, in which Tom focuses on this municipality. In this third turn constructional unit [10], Tom acts as a spokesman of the municipality of Valbonne ${ }^{3}$ : he literally speaks on behalf of them and reports a question whose principal author is the municipality administration. Through this speech practice, he produces a local identity of mediator standing between the municipality and its citizens.

Moreover, this question is then expanded (1.12-15) so as to project four possible solutions. Tom establishes a contrast between a first collection of three possible answers and a second category, composed of a single choice. This contrastive structure provides the recipient with the possibility to anticipate what Tom says. Therefore a contrast between the three options (agriculture, habitat, economic) which were labelled as "urbanization" and a last one is introduced into the talk. The last choice has a specific stress, because it seems to be a type of choice which differs from the previous ones. It is introduced with a verb on which there is a strong emphasis: "conserver" - to maintain things as they are. Because the white zones were previously described as "natural spaces", it seems obvious, at this very moment of the turn, that this last option addresses them as such.

At the end of the turn, Paul begins to talk before Tom has completely finished his own turn. Nevertheless, this overlap is not problematic. Paul's contribution is both sequentially relevant to the previous question asked by Tom and locally relevant in relation to the termination of Tom's turn at talk [12]. Saying "green spaces" in overlap, Paul offers an answer to the question and, simultaneously, he anticipates what Tom is currently saying. For this reason, his turn is both an answer and a collaborative ending of Tom's turn.

If we re-introduce into the analysis the gestures and gazes of the parties we discover that Tom has pointed alternatively to the two main areas of the map in which the white zones are represented. This has been done with a move of his left hand, which was reenacted three times. First, during the short pause after "savoir" (know); then, it takes the form of a faster move during a second brief pause after "vous " (you) and finally at the end of "conserver" (maintain). To focus on this last repeat, the first pointing component (Fig. 2) occurs while he is uttering "maintain" and the second during a short silence just after the same verb (Fig. 3). When he introduces the following noun, he gazes at Paul who then produces this terminal onset in overlap and turns toward him (Fig. 4). Through these three reiterations of the "same" hand trajectory above the screen, Tom progressively highlights a collection of the three white zones.

\footnotetext{
${ }^{3}$ Following Goffman [11], Tom is the animator, the party who has uttered these words, but the principal, the party who is socially responsible, is the municipality. Tom is putting the municipality "on stage" as a character.
} 


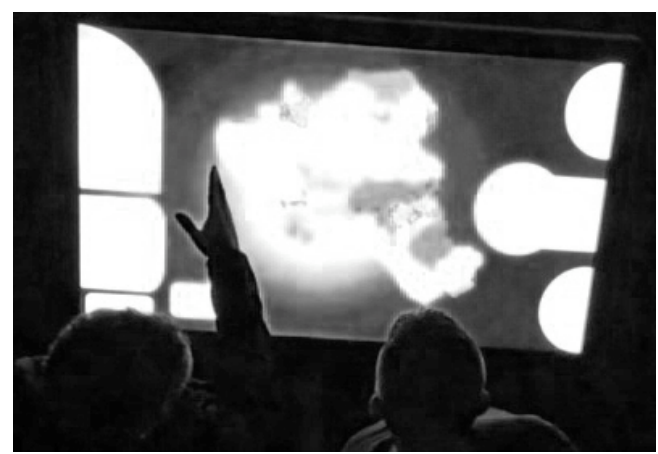

Fig. 2. Tom : conserver maintain

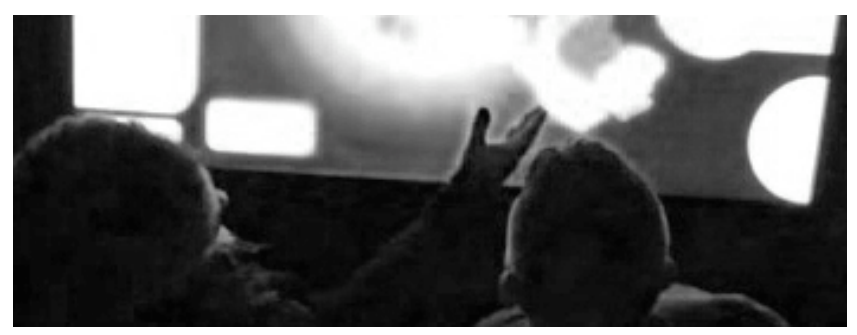

Fig. 3. Tom : (.)

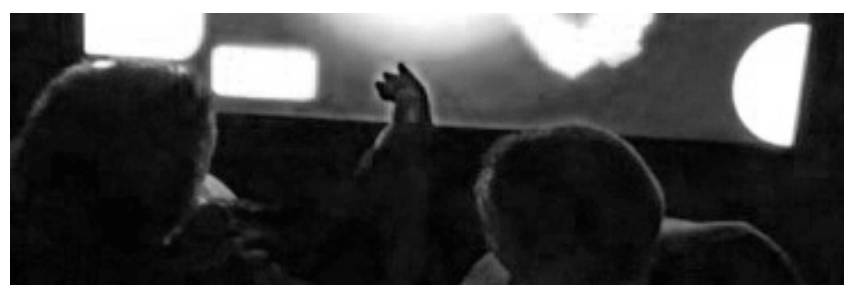

Fig. 4. T voc [espaces natu]rels naturel spaces Paul [les espaces verts]green spaces

This pointing gesture is oriented to two areas of the map in which there are white zones. First, Tom's hand gesture heads to the first white zone on the upper left area in the map, then it moves down to a second area at the bottom of the map where the two other white zones are situated (See Fig.1). The trajectory of this gesture is similar to the two preceding ones but its relation to the talk is different. The hand gesture immediately precedes the introduction of the deictic ("ces" (these)) and the category "espace naturels" (natural spaces). Thus the gesture can be seen not only as a referential pointing to the white zones but also as helping to project the category itself. Indeed, the white zones have been previously characterized as "natural spaces". This is exactly what the recipient does, since he produces a terminal overlap with this same category ("espaces verts" (green spaces)).

Tom himself quickly confirms this "invited" contribution with an acknowledgement token. Simultaneously, he begins to point to one of the three white zones on the 
screen. From this very moment, Tom gets involved into a course of action on the screen while uttering several affiliative displays towards Paul's turn at talk. Tom takes charge of the manipulation without inviting Paul to do it.

With emphasis, Paul expresses a general wish for the preservation of the natural space. This utterance is designed as the delivery of a personal preference for the preservation of the natural spaces in Valbonne. Because it is built as an emphatic expansion of the previous answer, the turn does not contribute to the progression of the game by itself. Therefore Tom produces several affiliative displays at relevant places while completing the selection process of the corresponding item of the menu. $\mathrm{He}$ maintains an orientation towards both the talk and the selection process on the screen. Through this dual orientation, he displays a minimal, positive involvement as a recipient of Paul's talk while being able to for the progressivity of the game.

Our analysis shows in detail how Tom's and Paul's vocal and non vocal contributions, their more and less direct involvement into the manipulation of the interface, and their practical understanding of what the installation is about progressively emerge as a temporal configuration of the very circumstances they produce. This configuration is created and maintained by and through their interactively achieved embodied interactional work in front of and with the central monitor. While Paul finds in the developing course of Tom's initial turn at talk an opportunity to express his opinions as a citizen, Tom becomes focused on the manipulation of the interface by which he enters Paul's verbal preferences into the system. This framing of their mutual participation, which is also a framing of the installation, is an emerging feature of the very configuration they produce rather than the output of a cognitive or deliberate choice. We will now turn to a visit where, though the animator theatrically stepped aside, he remained nevertheless close to the screen, and was thereby able to monitor the activity.

\subsection{Assembling the Collective}

This section will be devoted to an excerpt of the visit of Ecotype by a group of elders of the municipality. Composed of four women and one man, the group is assisted by a younger woman. The animator of the visit is Jack, the other designer of Ecotype.

Once the group has gathered under the dome, Jack starts the announcement, after which he provides numerous explanations on the game, both on the logic of the game and on practical aspects of playing. When he delivers these explanations, he stands in front of the screen, facing the visitors who are spread around in a semi-circle, the elderly women being seated on chairs. When he is finished, he says "It's up to you" and moves to the right side of the screen, leaving the place of the player to be occupied by whoever wants to. Compared to the previous fragment, this simple move contributes to a distinct participation framework: Jack delegates the manipulation of the interface to the visitors, but stays close to it for all practical purposes.

One of the consequences of this opening is that it does not tell the visitors "what to do next", nor which member(s) of the group should do it. A selection process must then take place: after a moment of hesitation, one of the seated women invites Ann, the younger woman, to "do it", which she declines with laughter. Then Ann invites Tim, the elderly man standing at the left side of the screen, to go. 
The analysis of this sequence will be based on the transcription below. Lines 3, 5 and 7 account for Tim's move towards the screen, which is completed at the end of line 7. Lines 10 and 13 account for Tim's hand gestures towards zones 1 and 3 on the screen (1. 10) and towards the meadow outside the dome (1. 13). These lines are simultaneous with the preceding vocal transcription lines.

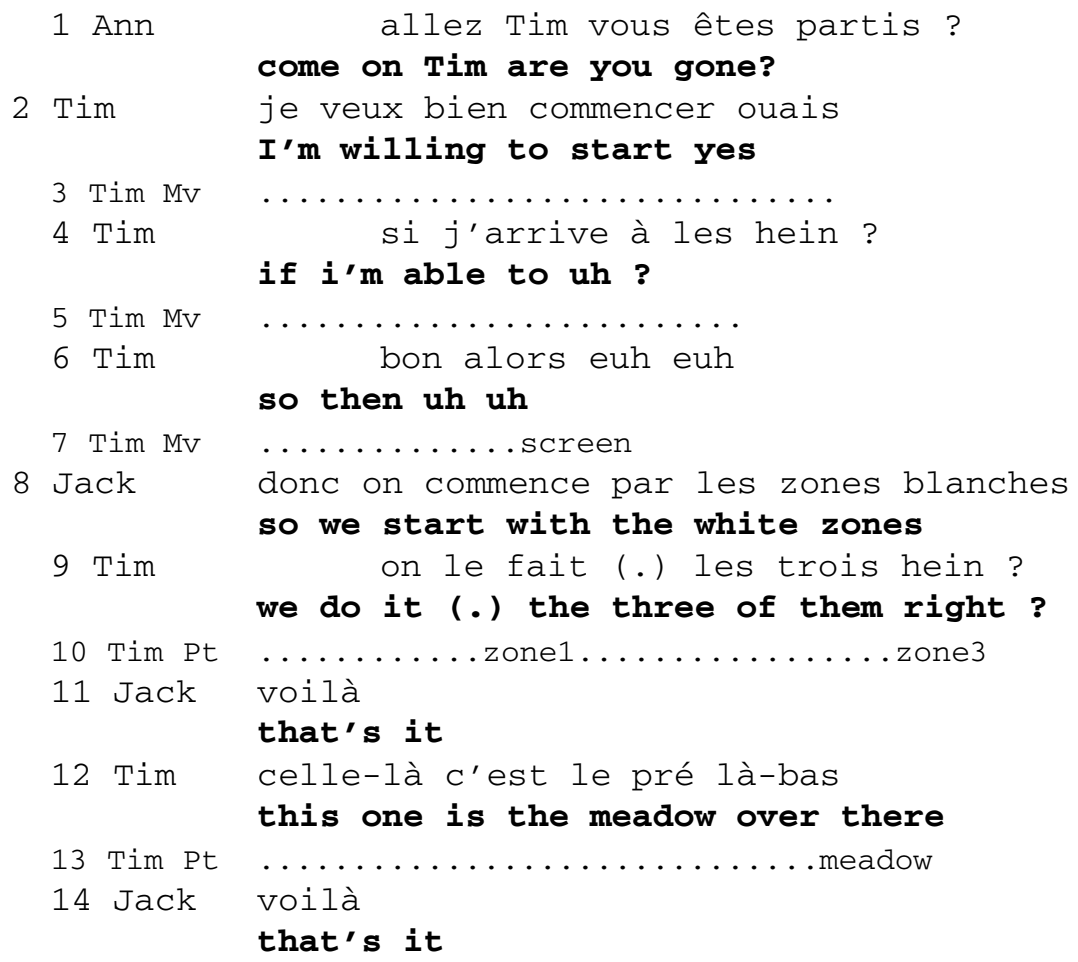

Tim replies to Ann's invitation with a guarded acceptance (1. 2). The acceptance is also made accountable by his simultaneous move to the front and centre of the screen $(1.3,5,7)$, where he minimally expresses his willingness to engage his task without knowing exactly how (1. 6). The accountability of Tim as the player is then acknowledged by Jack, the animator standing on the right side of the screen. Jack's turn is a mix of an instruction and an explanation (1. 8), and as such is not only addressed to Tim but to Tim as the player.

This specific address is in turn ratified by Tim who replies to Jack by asking a somewhat technical question (1. 9), thus confirming the categorial pair of player and animator. The relevance of the pair is strengthened by the tag question format adopted by Tim, which triggers an immediate ratification by Jack (1. 11).

Note that when Tim formulates the question, his right hand points to two zones of the map (1. 10). In other words, Tim uses a resource made available by his move towards the screen. Due to his position on the right side of the screen, Jack is able to see Tim's gestures, which is not the case of the elderly women who are still seated two meters behind the screen. 
Tim's and Jack's body orientations display a co-involvement into a main activity. Their shoulders being oriented to the command screen, they are able to "gaze together" at the relevant zones. Through this body arrangement, they display both a common interest in the activity which takes place and a co-membershiping status in the making of this same activity.

Tim then engages in a series of three similar operations. Only the first appears on the transcript above (1. 12-13). The operation consists in pointing to one of the three zones on the screen and relating them to some items of local knowledge. In the first question, a point on the screen ("this one") is related to a point in the world outside the dome ("the meadow over there"). Both highly indexical expressions are made intelligible by accompanying pointing gestures, the first on the screen, the second outside the screen and even outside the dome. Through this "double indexicalization", Tim displays his ability not only to relate particulars of the map to his local knowledge but also to locate the whole Ecotype device in the surrounding environment. Even if it is not formulated as a question, Tim's utterance is followed by a confirmation by Jack (1. 14).

This analysis shows that Jack delegates the manipulation of the screen but remains close to the centre of the activity. It does not necessarily mean that he controls the player's behaviour. It appears that standing in front of the screen provides Tim with opportunities to exploit his extended knowledge of the territory, exhibiting thereby the relevance of his selection as the player.

This second socio-material configuration rests on a quasi face-to-face relationship which takes place over the screen. In this case, the player turns out to be the main manipulator: he selects himself the relevant menu items while being watched over by the animator. Since Tim is surrounded by other members of the group of visitors, the animator has left his usual front position to go to the other side of the screen. This configuration, which emerges from the selection process, produces specific pragmatic possibilities for the development of the visit. No one has decided to create this configuration. Nevertheless, once instantiated, it provides the participants with opportunities to act and to relate to the artefacts in certain ways.

\section{Conclusion}

The accountable features of the activity have been assembled by the in-situ articulation of talk, gestures and postural arrangements. How exactly the participants are acting together, as citizen trying to influence the future urban development of their municipality, as people sharing a common concern about energy consumption, and what they are doing with the artefact, playing a serious game or being involved into a democratic consultation, are not provided for by the artefact capabilities nor by some hidden social or psychological processes. The qualities of the co-participants emerge from the interactional process through which they discover what can or cannot be done with the artefact. We have shown that the animator takes part in this process without being able to fully control its trajectory. Two configurations in which humans and artefacts are both creatures and creators have been elucidated thanks to a detailed analysis of video recordings of embodied action. 


\section{References}

1. Reeves, S.: Designing Interfaces in Public Settings: Understanding the Role of the Spectator. In: Human-Computer Interaction. Human-Computer Interaction Series. Springer, London (2011)

2. Heath, C., Luff, P., vom Lehn, D., Cleverly, J.: Crafting Participation: Designing Ecologies, Configuring Experience. Visual Communication 1, 9-34 (2002)

3. Garfinkel, H.: Studies in Ethnomethodology. Prentice Hall, Englewood Cliffs (1967)

4. Dourish, P.: Where the Action Is: The Foundations of Embodied Interaction. MIT Press, Cambridge (2001)

5. Vom Lehn, D., Heath, C., Hindmarsh, J.: Exhibiting Interaction: Conduct and Collaboration in Museums and Galleries. Symbolic Interaction 24(2), 189-216 (2001)

6. Vom Lehn, D., Heath, C., Knoblauch, H.: Configuring Exhibits: The Interactional Production of Experience in Museums and Galleries. In: Knoblauch, H., Kotthoff, H. (eds.) Verbal Art across Cultures: The Aesthetics and Proto-aesthetics of Communication, pp. 281-329. Gunter Narr Verlag, Tubingen (2001)

7. Goodwin, C.: Action and Embodiment within Situated Human Interaction. Journal of Pragmatics 32, 1489-1522 (2000)

8. Streeck, J., Goodwin, C., LeBaron, C. (eds.): Embodied Interaction: Language and Body in the Material World. Cambridge University Press, Cambridge (2011)

9. Jefferson, G.: Transcript Notation. In: Atkinson, J.M., Heritage, J. (eds.) Structures of Social Action: Studies in Conversation Analysis. Cambridge University Press, New York (1984)

10. Sacks, H., Schegloff, E.A., Jefferson, G.: A simplest Systematics for the Organization of Turn Taking for Conversation. Language 50(4), 696-735 (1974)

11. Goffman, E.: Footing. In: Goffman, E. (ed.) Forms of Talk, pp. 124-159. University of Pennsylvania Press, Philadelphia (1981)

12. Jefferson, G.: Notes on Some Orderlinesses of Overlap Onset. Tilburg Papers in Language and Literature (Tilburg University) 28, 1-28 (1983) 